\title{
Jesús María Nieto Ibáñez, Historia antigua del Cristianismo, Madrid, Edito- rial Síntesis, 2019, 265 pp.
}

La editora que ha publicado este libro lleva por nombre el propio lema cultural/ educativo que la distingue, porque su catálogo está integrado por títulos que se ajustan al proyecto de difundir "síntesis" de saberes relacionados con diferentes áreas de conocimiento. El tipo de obras que saca a la luz este sello editor se destina con preferencia a los ciclos formativos universitarios y abarca numerosos campos disciplinares, entre ellos el de la historia en sus diversas edades, y en la antigua concretamente se inscribe la publicación objeto de esta reseña, Historia antigua del Cristianismo.

No resulta sencillo llevar a cabo una monografía que sintetice todos los conocimientos concernientes a una materia determinada. Se requiere en primer lugar que el autor que acometa una tarea de tales características sea un especialista en esta área concreta, o bien que en él concurran conocimientos interdisciplinares que le faculten para abordar el encargo editorial. Aún así, es tarea muy laboriosa y compleja la encomendada, porque han de conjugarse en el cometido no pocas destrezas técnicas que complementen consolidadas bases científicas.

Jesús María Nieto Ibáñez, catedrático de filología griega en la Universidad de León, y director del Instituto de Humanismo y Tradición Clásica de dicha Universidad, demuestra en este nuevo aporte bibliográfico haber superado con creces el desafío que le planteó este proyecto, para el que ciertamente le facultaban sus bien acreditadas competencias filológicas. Y no solo por el magisterio obvio que posee en lengua y literatura griega, sino en virtud de tantos estudios dedicados desde hace no pocos años a asuntos, subgéneros y autores con incidencia en el entramado de la labor historiográfica puesta en práctica en esta Historia antigua del Cristianismo.

Aludía, por ejemplo, a investigaciones suyas sobre asuntos relevantes de las letras veterotestamentarias, patrológicas, judaicas, del humanismo bíblico; a temas relacionados con el santoral, como su excelente trabajo sobre San Cosme y San Damián; a contribuciones acerca de subgéneros como el profético, y el oracular; y a autores, en fin, como Flavio Josefo. El bagaje de estos antecedentes le predispuso para asumir la confección de un libro que, además, no hubiera podido culminarse con tanta eficiencia sin el concurso y dominio del griego y de la cultura helénica que atesora Nieto Ibáñez. En este caso una lengua y una cultura, la helenística, sin la cual el Cristianismo no se hubiera desarrollado como lo hizo desde una Palestina que, a partir de la conquista de Alejandro el Magno, más de trescientos años antes del nacimiento de Cristo, ya comenzó a helenizarse.

Esta Historia antigua del Cristianismo consta de media docena de capítulos, sobre los que construiré el cuerpo de esta reseña, dado que en él se concentra la mayor parte de la textualidad debida al autor, y de un amplio, selecto y pertinente muestrario de 
textos que ilustran las principales informaciones historiográficas expuestas en la obra. Sigue después una cronología muy útil en la que la secuencia de los emperadores y sus respectivos años de mandato resulta inapreciable para el encuadre de los acontecimientos históricos fundamentales con incidencia en el devenir del Cristianismo, así como para la contextualización de los escritos de vario signo de autores cristianos que se inscriben en ella. El libro se completa, finalmente, con el puntual repertorio bibliográfico de fuentes primarias, a las que siguen otras obras que también fueron objeto de consulta.

En el preliminar recuerda el autor que el Cristianismo es un fenómeno histórico mediterráneo, y está ligado a la historia de la propia Europa. La religión cristiana es, como bien sabemos, de origen semita, pero no suele repararse en que "se heleniza hasta el punto de suplantar a los cultos helenísticos" (10), se señala. Resalta también Nieto Ibáñez el hecho de que no iba a ser Jerusalén, sino Roma, desde donde se expandieron las creencias cristianas, y asimismo que no fue Jesucristo, sino Pablo de Tarso, quien fundamentó sus bases doctrinales.

No menos sorprendente sería que el nuevo credo, al principio muy minoritario, y heterodoxo respecto al judaísmo, acabó convirtiéndose en religión oficial de un vasto Imperio, representando la ortodoxia en materia de fe, y siendo la única religión permitida legalmente. Eso supuso que, de religión perseguida, pasase a religión amparada, y después a oficial, no tardando en ser a su vez perseguidora.

Decisiva fue en las singladuras iniciales del Cristianismo la labor proselitista comenzada sobre todo en Alejandría por las comunidades judías en lengua griega, elaborándose en esa ciudad la más antigua versión al griego de la Biblia hebrea, la conocida como Septuaginta, cuya repercusión habría de ser de un alcance incomparable. Otro hito en la expansión del Cristianismo habría de serlo el conocido como Concilio de Jerusalén, que contó entre los asistentes a los propios apóstoles, y en el que participarían Pedro, Pablo y Santiago el mayor, a quien la tradición atribuye ser hermano de Jesús. En ese foro el Cristianismo trocó su designio, pasando de nacional a universal, lo que tuvo lugar en el contexto del "judaísmo helenístico", es decir en el judaísmo expresado en lengua griega. Y también fue allí donde se emplearía por vez primera el nombre de cristiano aplicado a los creyentes en el mensaje de Jesús de Nazaret.

En la primera mitad siglo III alcanzaría el Cristianismo su madurez, explica Nieto Ibáñez, situando la culminación de su período primitivo en el año 451, merced al Concilio Ecuménico de Calcedonia. Fue en ese cónclave donde también se produjo la división entre los cristianos católicos y los ortodoxos, al tomarse el acuerdo de que la Iglesia de Constantinopla tendría el mismo rango religioso que la romana. La evolución de ambas iba a ser, sin embargo, muy distinta, toda vez que el Imperio de Bizancio, desde el siglo VII, fue invadido por un nuevo monoteísmo, el musulmán.

Entre las numerosas causas que contribuyeron a que el credo cristiano se expandiese, el profesor Nieto Ibáñez destaca varias: su apertura a mujeres, a esclavos y a extranjeros; su decantado social en un contexto en el que Estado no lo contemplaba; el hecho de que no requiriese a sus adeptos preparación previa alguna; y haber acertado 
a dar, en aquella encrucijada histórica, una respuesta a las necesidades humanas que fue considerada más valiosa para la gente que la ofrecida para las religiones mistéricas.

Se remarca después que el contexto histórico en el que nacería Jesús fue el del mandato de Augusto, cuando Palestina formaba parte del Imperio romano, siendo anexionada por Pompeyo a la provincia de Siria con un estatuto especial. Su predicación pudo comprender entre uno y tres años, durante los tiempos de Tiberio, bajo cuyo período se produjo su muerte en cruz, condenado a dicha pena por el prefecto o procurador Poncio Pilato, ya que era ese el castigo entonces de aplicación a quienes se acusaba de un crimen político no teniendo ciudadanía romana. La acusación atribuida al reo fue la de haberse abrogado ser rey de los judíos, lo que suponía su rebeldía contra las leyes romanas vigentes. Jesús hablaba en arameo, pero apunta Nieto Ibáñez que en modo alguno ha de descartarse que conociese la lengua griega, "por las citas que, según el Evangelio, hace al texto de la Septuaginta." (31)

Jesús no iba a ser quien fundase el Cristianismo, se argumenta en la obra, y tampoco la institución que llamamos su Iglesia. Él habría instituido el Bautismo y la Eucaristía, eso sí, pero no el sacerdocio ni la autoridad episcopal. Habiéndose rodeado de doce apóstoles en atención a las doce tribus de Israel, el apóstol que hizo trece, Pablo de Tarso, que no solo no le había conocido en persona, sino que había sido un contumaz perseguidor de los creyentes en el crucificado, sería quien fundase en realidad el Cristianismo, imponiéndose su lectura propia de la significación cristiana sobre cualesquiera otras interpretaciones.

A Pablo se debería la tesis de que Cristo expió las culpas de los hombres todos al ser crucificado, habiendo nacido para esa expiación. A él se debió también el cambio de su tratamiento, desde el judío de Hijo del hombre, al de Señor, de influjo helenizante. Asimismo motivó el cambio del paradigma apocalíptico de la iglesia primitiva por el ecuménico helenista romano. Sin embargo, su aporte más sustantivo fue el de concebir un concepto de salvación inclusivo, porque comprendía a todos los hombres, sin limitarlo a los judíos. El capítulo primero finaliza señalando los dos signos diferenciales del Cristianismo. Uno es el Bautismo, que origina el hombre "nuevo" frente al "viejo", en base a la tesis manifestada por Pablo en una epístola a los Colosenses, y que con los siglos sería asumida, dándole otro sentido, por ideologías muy distintas. Otro es la Eucaristía, en virtud de la cual efectúa el creyente la comunión con el propio Jesucristo.

Concentrándose Nieto Ibáñez en el Cristianismo primitivo, se detiene en el Concilio de Jerusalén, al que ya se aludió. Este cónclave supuso el punto de partida de una religión nacional, la judaica, en otra distinta y universal, la cristiana. Sigue un epígrafe relativo a la fundación de la Iglesia, hecho en el que Jesucristo no habría participado, aunque el evangelista Mateo, y solo él, sí asegura que lo hizo. Se explica luego la peripecia histórica de la Iglesia de Jerusalén, de sus facciones primeras, así como la de los cristianos gentiles. Seguidamente, se da cuenta de las zonas por las que se fue extendiendo el Cristianismo (Palestina, Roma, Egipto, Siria, y otros lugares del Asia Menor, así como Mesopotamia, Persia, Norte de África e Hispania). 
Datos a retener, entre otros, son los que se refieren a las lenguas utilizadas, subrayándose que la primera oficial del Cristianismo fue el griego, pero ya en el siglo III se consolidaría el latín. Sin embargo, los coptos desarrollarían en Egipto, en el IV, una escritura en su propio idioma para traducir y leer los textos sagrados cristianos. Destacable resulta que en Antioquía se desarrollase el maniqueísmo, una religión de carácter híbrido que "mezcla elementos religiosos autóctonos con otros del budismo, del arrianismo, además de contar con principios gnósticos y un destacado dualismo." (58) Vale la pena retener en la memoria esa tan temprana hibridación en unos tiempos como los nuestros en los que tanto se ponderan positivamente las hibridaciones. Por lo que hace a Hispania, se recuerda las posibles visitas de Santiago el mayor y de Pablo, que habría visitado Tortosa y Tarragona, de donde era obispo el primer mártir hispano, Fructuoso, en tiempos del emperador Valeriano.

"El Cristianismo en el Imperio romano" es el título del tercer bloque textual, que principia con referencias a informaciones más o menos precisas sobre la nueva religión debidas a historiadores romanos como Flavio Josefo, Suetonio y Tácito. Dato que siempre será llamativo es el de la crítica tan acerva contra los cristianos que esgrimió Marco Aurelio, emperador de un Imperio en principio condescendiente con el nuevo credo, un credo que en realidad se mostraba intolerante en contra de los cultos religiosos practicados entonces, porque se les veía como incompatibles con él.

Distintivo en el Cristianismo fue que, entre otros aportes, ofrecía la posibilidad de una vida eterna después de la muerte, lo que no contemplaban otras religiones. En el ámbito cívico abogaba por el antibelicismo y estuvo en contra de los modos de ser ciudadano que prescribía el sistema legal como aceptables, por ejemplo el de tan grueso trazo de enviar a seres humanos a la muerte en el circo, y me refiero a los cristianos, en más de una ocasión. Así ocurrió -recuerda Nieto Ibáñez- con el martirio de Policarpo o los mártires de Lyon del año 177, que fueron arrojados a las fieras con ocasión de una festividad." (76)

Seguidamente se van relatando los avatares por los que pasó el Cristianismo desde los Flavios a Diocleciano, un período extenso en el que se irían alternando persecuciones con épocas más llevaderas. Los puntos abordados luego por el autor pivotan en torno a la legalización del Cristianismo y a su triunfo con Constantino, con la posterior oficialización, no sin que hubiese el paréntesis en la misma ocasionado por Juliano el Apóstata.

Por sus repercusiones en la historia de Occidente resulta muy remarcable el hecho de que en ese antiguo Cristianismo se hallen las bases de la idea del gobernante, del príncipe, del Emperador si se quiere, que encarna un orden cristiano en el mundo, y que en consecuencia obedece y defiende el credo cristiano y a su institución eclesial, además de comprometerse en expandir esa creencia por doquier.

Varias páginas dedica Nieto Ibáñez a cómo se fue configurando la nueva sociedad presidida por el Cristianismo, al papel que en ella desempeñaron las mujeres, así como a los grupos de creyentes cristianos que podían distinguirse en el nuevo tipo de sociedad lograda, en la que se impuso el antijudaísmo, religión que llegaría 
a proscribirse, lo que no había ocurrido en tiempos pretéritos. Los vetos represivos iban a consistir en "la prohibición de matrimonios mixtos, de ocupar cargos públicos por parte de los judíos, de construir sinagogas y de hacer propaganda para ganar prosélitos." (99)

En la "Organización y cultos de la Iglesia" se centra el bloque cuarto del libro, el cual se abre recordando que la idea de que los fieles se llamasen entre sí "hermanos" data de los primitivos tiempos. También se señala ahí que fue Ignacio de Antioquía quien primero empleó el término "universal, católico" en referencia a la Iglesia cristiana, una Iglesia que reprodujo estructuras romanas al organizarse. Por tanto, la unidad básica fue la ciudad, estando al frente de ella como pastor un obispo, denominándose metropolitano el que regía a los obispos locales de una provincia eclesiástica, y siendo la diócesis la agrupación de varias de ellas. Por encima de los obispos metropolitanos se situaban los primados, o patriarcas, consolidándose, entre el 381 y el 451, un Patriarca de Occidente (Roma) y hasta cuatro de Oriente (Constantinopla, Alejandría, Antioquía y Jerusalén). Respecto a la denominación de Pontífice, como es sabido reservada en el Imperio romano a los emperadores, en el siglo V se aplicaría al Papa de Roma.

Si el más lejano de los Concilios fue el de Jerusalén, que tuvo lugar en el 59, el más antiguo de los celebrados en España iba a ser el de Elvira, efectuado en Granada entre el 300 y el 303. En Concilios posteriores, los de Nicea y Constantinopla, los debates principales giraron en torno a las relaciones entre Padre e Hijo, incluyéndose más tarde en la cuestión el Espíritu Santo. El de Constantinopla establece el dogma de la Santísima Trinidad, proclamando que dicha tríada constituye "una sustancia y tres personas" (113). El Concilio de Éfeso, en el 431, refrendó el 'monofisicismo', a la vez que acuerda que María no es Madre de Cristo, sino Madre de Dios. El Concilio de Calcedonia, en el 451, aprobó un canon de carácter estructural por el que establecieron dos modelos eclesiales, el romano y el ortodoxo y griego.

En este capítulo refiere Nieto Ibáñez los ritos practicados por las comunidades primitivas, las fiestas que celebraban, los ciclos litúrgicos consagrados, entre ellos el de la Navidad, fijándose el 25 de diciembre el nacimiento de Cristo, en sustitución de la fiesta en la que los paganos rendían culto al Sol y al dios Mitra, en el solsticio de invierno. De esta manera se significaba que el nacido, la luz, vencía a la oscuridad. Se detiene luego el autor en el rito de la celebración dominical eucarística, así como en los sacramentos de la penitencia y del matrimonio antes de los epígrafes referentes al culto a los mártires y al monacato.

Entre las distintas explicaciones que conciernen a dichos puntos, resultan de especial interés las relativas al matrimonio. Nieto Ibáñez recuerda que San Pablo enseñaba que la esposa debía ser respetada por el marido, pero a la vez tenía que temerle. En la Iglesia primitiva se aceptó el concubinato entre personas solteras. El vínculo matrimonial podía disolverse, pero en el supuesto de apostasía. En paralelo, no se permitieron los matrimonios mixtos entre alguien cristiano y otra persona que profesase una religión distinta. El matrimonio cristiano no afecta a la diferencia de 
clases de los contrayentes. Es más: incluso una persona libre podía casarse con otra que fuese esclava,

Entiendo que, con lo hasta aquí referido, los lectores de esta reseña habrán podido calibrar suficientemente la clase de aportes de este libro. Por esta razón no vamos a seguir resumiendo algunas de las muchas informaciones de los capítulos restantes de que consta. Respecto al que hace cinco, digamos escuetamente que se concentra en la dialéctica entre ortodoxia frente a heterodoxia, primero durante los siglos II y III, y luego en la centuria cuarta. Tocante al capítulo seis, titulado "Legado y testimonio escrito, La literatura cristiana", tiene un gran nivel y extensión, resultando en este sentido el más prolijo y de más enjundia para los filólogos.

En esta monografía historiográfico-didáctica, Nieto Ibáñez nos remarca en su prólogo que no tiene carácter interpretativo, un propósito que se cumple de manera sistemática, y que los lectores comprobarán a lo largo y ancho de su labor de acopio y explicación de tantas informaciones eruditas manejadas cuidadosamente. Al propio tiempo es seguro que no pocos van a ir reparando, en los diversos capítulos, en cómo muchas de las realidades y creencias sucedidas a partir de la cronología final de este libro, y por supuesto en los siglos XX y XXI, tienen su origen en acontecimientos y en concepciones que constan en esta obra.

En esta Historia antigua del Cristianismo se aporta un bagaje indispensable para todo aquel que cultive cualquiera de las ramas de las ciencias humanas, entre ellas la de los estudios de obras literarias, donde acaecen tantos supuestos que se entenderán mejor si se tienen en cuenta tantas peculiaridades como se involucran en esta religión que afecta y ha dado y seguirá dando pie a tantas creaciones artísticas. También apreciarán los lectores de este libro que el Cristianismo no constituye un todo monolítico que admite ser evaluado con generalizaciones centradas en un período único de su historia, y ni siquiera en un emplazamiento único en el mapa geográfico y cultural, como foto fija inamovible, sea la que sea, sino que sus avatares han sido numerosos, cambiantes y complejos, y todos lo representan en alguna y distinta medida.

José María Balcells 